\title{
Adornos confeccionados con cabellos humanos. De la Era Victoriana y de Nuevos Diseñadores
}

Beatriz Ferreira Pires *

\begin{abstract}
Resumen: La época victoriana impuso el luto abiertamente, estableció el negro como color oficial de las vestimentas e introdujo en el mercado la producción de adornos, tanto residenciales como corporales, confeccionados con cabellos humanos. Tales adornos, al ser hechos con materia prima orgánica proveniente del cuerpo de un ente querido, garantizaban que éste no fuera olvidado. Contemporáneamente, este mismo material es utilizado por algunos diseñadores de joyas.

La posibilidad de utilizar material humano para confeccionar estos ornamentos ocurre, a través de los siglos, debido a los cambios en la percepción de la muerte y cómo ésta es representada; cómo el cuerpo muerto es cuidado y enterrado.
\end{abstract}

Palabras clave: Cabellos - Joyas de Luto - Muerte - Edad Media - Era Victoriana.

[Resúmenes en inglés y portugués en la página 201]

${ }^{(*)}$ Arquitecta, artista plástica, profesora e investigadora del Curso de Textiles y Moda de la EACH/USP. Posee Post Doctorado (FAPESP/2009) por el programa Moda, Cultura y Arte Centro Universitario SENAC-SP. Doctorado (FAPESP/2006) en "Educación, Conocimiento, Lenguaje y Arte” - FE/UNICAMP. Maestría (CNP/2001) - IA/UNICAMP. Autora de los libros: "O Corpo como Suporte da Arte". SENAC, 2005; "Corpo Inciso, Vazado, Transmudado - Inscrições e Temporalidades". Annablume/FAPESP, 2009. Autora y organizadora - juntamente con Patricia Dora e Denise Trindade del Cuaderno del Centro de Estudios en Diseño y Comunicación - N ${ }^{\circ}$ 58, Año XVI. Facultad de Diseño y Comunicación - Universidad de Palermo / Argentina, 2015. Autora y organizadora -juntamente con Suzana Avelar e Cláudia Garcia- del libro: Moda, Vestimenta, Corpo. Estação das Letras e Cores, 2015.

\section{Introducción}

El animal, el solamente-viviente, no muere, pero deja de existir (Agamben, 2006, p. 13).

La actitud del hombre frente a la muerte y los ritos que la envuelven no fueron siempre los mismos. Sus variaciones, que están relacionadas principalmente a la formas como ella 
es aceptada, están asociadas a diferencias culturales y a los periodos históricos en que ocurren. Dentro de estas variantes, tal vez la materialmente más perceptible, sea la que se refiere al modo en que el cuerpo muerto es cuidado y sepultado.

El periodo en el cual surgen innúmeras variaciones, no sólo en cuanto a la forma como el cuerpo muerto es recibido y tratado, pero también referente al modo en que el cuerpo es percibido y abordado por la Iglesia Católica, es la Edad Media.

La breve descripción a seguir sobre formas de sepultación se basa en la obra "El Hombre Delante de la Muerte" de Philippe Ariès (2014).

Aunque los antiguos establecieron una relación de familiaridad con la muerte, el espacio destinado a los cadáveres -enterrados o incinerados- debería ser implantado en locales distantes de los ambientes, privados o públicos, destinados a los vivos. Tal norma se originaba en el temor que los vivos tenían de los muertos; en lo que se refiere a la parte inmaterial, que se traducía en la posibilidad del alma del muerto volver; como también en relación a la parte material, que se basaba en la posibilidad de que los restos mortales descompuestos, o los provenientes de combustión, los contaminaron con sus impurezas. Como parte de esta reglamentación, Ariès (2014) cita parte del contenido de la tabla número diez perteneciente a la "Ley de las Doce Tablas" -legislación romana escrita alrededor de 450 A.C. que estipula lo siguiente: "Ningún muerto será sepultado o incinerado dentro de la ciudad" (Ariès, 2014, p. 40). El miedo de contagio, fue reemplazado por el miedo de violación de la sepultura. En lo que se refiere al primero, por los motivos dispuestos, el agente del daño era el cadáver y la víctima era el ser viviente, en el segundo las posiciones se invirtieron, la víctima era el cadáver que tenía su reposo perturbado por la violación de su sepultura, por los seres vivientes. El temor que este acto despertaba era debido a la fe en la resurrección de los cuerpos y a la creencia de que tal profanación sería perjudicial al despertar del muerto para la vida eterna, que se daría en el día del juicio final.

El miedo de que los túmulos sean profanados, hizo que sean dislocados hacia las proximidades de las sepulturas de los mártires. Los mártires ciertamente protegerían los cadáveres y expulsarían a los violadores. Como las sepulturas de éstos también se localizaban en las afueras de la ciudad, en las necrópolis comunes, tal traslado no ocasiono alteración en la distancia entre las áreas destinadas a los vivos y a los muertos. Este cambio solamente ocurre con el crecimiento de las ciudades. Alcanzadas por las áreas destinadas a los vivos, las áreas destinadas a los muertos, todas ellas se desordenan y se mezclan.

La nueva situación espacial sepulta los antiguos miedos y las ciudades pasan a abrigar tanto a los vivos, como a los muertos. Procedimiento iniciado cuando la creación y legitimación del espacio destinado a los muertos se relaciona a la construcción de una iglesia Es de esta conjunción que nace uno de los primeros términos utilizados, en la lengua francesa, para designar lo que hoy se conoce como cementerio. Los términos son: adro -pequeño "patio externo descubierto y, a veces, cercado; localizado frente o entorno a una iglesia" (Ariès, 2014, p. 40) y osario (charnier) - "gaveta o urna en que se sepultan los cadáveres"; "galerías cubiertas, capillas funerarias, osarios" (Ariès, 2014, p. 74).

Con el objetivo de solucionar el problema relacionado a las áreas destinas a las sepulturas, que eran insuficientes para atender a la población, se instituyó el procedimiento del reaprovechamiento de las tumbas. Para lo cual, viejos huesos secos eran retirados de la tierra y depositados en un otro espacio, dentro de la misma área. El espacio para el cual 
estos huesos eran trasladados recibe el nombre de osario. "El trazo más extraordinario del osario es la exposición de los huesos" (Ariès, 2014, p. 79). En el inicio los huesos eran colocados de forma desordenada en estos espacios, pero, "a partir del siglo XIV bajo la influencia de una sensibilidad orientada para lo macabro" (Ariès, 2014, p. 82), ellos fueron separados por tipos y dispuestos de modo que hagan formas armónicas.

Haciendo un paréntesis, el término macabro del francés "(danse) macabre-danza alegórica medieval que simboliza la muerte" ${ }^{2}$, surge en este siglo, más precisamente en el año 1376; en la frase "Je fis de Macabre la danse" (yo hice la danza Macabra) escrita por Jean Le Fèvre, en el poema Respit de la Mort. De acuerdo a Huizinga, tal término acrecentó a la muerte y a las cosas a ella relacionadas sensaciones que ampliaron las impresiones de horror. "A la idea de la muerte se mezcló un elemento nuevo, fantástico e hipnotizante, un escalofrío que brotó del área consciente del gélido pavor fantasmagórico y del terror frío" (Huizinga, 2010, p. 231).

Volviendo a la exposición de los huesos, ésta evidenciaba la finitud de la vida, a semejanza, entre los seres vivientes es el irrefutable destino de todos. La misma falta de espacio, aliada a la condición financiera de los individuos que no tenían como pagar por el espacio ocupado, hizo surgir las grandes fosas comunes. Con dimensiones que variaban en torno de 4,5 metros de ancho por 4,5 metros de largo y 5,5 metros de profundidad, las tumbas podían contener unos quinientos cadáveres.

En ellas, lo que mezclaban no eran solamente huesos, aquellos que no determinan la semejanza entre esos seres, pero también, las carnes, aquellas que denuncian nuestras diferencias. En otras palabras, en las fosas comunes se mezclaban, no sólo aquello que nos da la idea que somos pertenecientes a una especie, pero también, aquello que hace que nosotros tengamos idea de nuestra individualidad.

La imagen de una fosa común, ciertamente, es más aterradora que la del osario. Esto ocurre porque la fosa es el escenario de todas las etapas de putrefacción del cuerpo. Es en ella que se da la putrefacción de la carne y de las vísceras. A sensación de malestar propiciada por estos dos elementos que componen el cuerpo está asociada a la viscosidad que las envuelve. Al contrario de la parte húmeda, huesos y cabellos se mantienen aceptables para ser vistos.

\section{De los cuerpos - de las Carnes y de los Huesos}

En la Edad Media, la acción de separar la carne de los huesos no era siempre delegada al proceso natural de putrefacción del cuerpo. Entre los siglos XII y XIII y, en algunas circunstancias determinadas, en el siglo XIV, ésta podía ocurrir por interferencia humana.

Cuando personas importantes morían en locales distantes de donde vivían, la imposibilidad de transportar esos cuerpos sin que éstos entraren en proceso de descomposición, hizo surgir la práctica de separar las partes suaves y viscosas del cuerpo de la parte dura y seca. El procedimiento ocurría de la siguiente forma: primeramente el corazón y las vísceras eran retirados del cuerpo, en seguida el cuerpo era cortado en pedazos y hervido durante el tiempo necesario para que los huesos se separen de la carne. Separados, corazón, vísceras, carne y huesos, podían ser enterrados en diferentes lugares. 
En los tres primeros eran sepultados juntos, en el local de la muerte, y los huesos eran enviados para el local de origen del individuo. En otros casos, la excepción era el corazón el que se depositaba en una caja con un lado, o más de uno, de vidrio. Los otros restos eran distribuidos de forma igual. De esta manera, los únicos elementos solemnemente depositados en la sepultura próxima al lugar de la residencia del muerto, eran los huesos. "Los huesos eran destinados al local de la sepultura más deseado, porque los huesos secos eran considerados la parte más noble del cuerpo, sin duda por ser la más durable" (Ariès, 2014, p. 345).

Esta idea persiste hace milenios en diferentes civilizaciones, la conservación del cuerpo está asociada, a la conservación del individuo y por tanto, al reconocimiento de éste, sea por sus iguales o, frente a las divinidades. Para los católicos de la Edad Media, que vivían en un ambiente impregnado de religión, los cuerpos que, cuando exhumados se mantenían conservados -total o parcialmente- eran los de los santos, figuras que les eran esenciales y familiares. Tener acceso visual a lo que resta de estos cuerpos era motivo de gran conmoción, del fortalecimiento de la fe, por consiguiente, la identificación con la obediencia hacia la religión.

Efectos tan favorables despertaban el deseo, tanto en las personas que recibían las bendiciones por entrar en contacto con lo que restaba de los cuerpos de los santos, como las que pertenecían al clero que disfrutaban de los beneficios que derivaban de la obediencia de los fieles que potencializaba tales resultados. La forma encontrada para alcanzar estos objetivos era diseminar estas reliquias entre templos y fieles detentores de prestigio y poder. Para eso, era necesario que las reliquias sean más numerosas. Fueron encontradas tres formas para satisfacer tal demanda; dos se relacionaban con reliquias verdaderas y la tercera no. La secuencia que sigue no es cronológica.

La primera aumentaba el número de objetos detentores de las gracias. De esta forma, además de los cuerpos de los santos, pedazos de sus ropas o de los objetos utilizados por ellos o contra ellos, en caso de haber sufrido torturas, eran catalogados como reliquias.

La segunda fragmentaba al máximo las partes remanecientes del cuerpo, para que de ellas surgirán la mayor parte de reliquias. La parte ideal para eso está formada por los cabellos. La tercera utilizaba elementos falsos. Se decía que era del santo aquello que no era. El anhelo de poseer una reliquia era tan grande que algunos fieles y algunos clérigos practicaban actos completamente crueles y nada católicos para conseguirlos.

Los monjes de Fossanuova, donde vivió Tomas de Aquino, temiendo que su valiosa reliquia se perdiera, no dudaron en decapitarlo y en cocinar y preservar el cadáver.

Antes mismo de que Santa Isabel de Turingia sea enterrada, una multitud de devotos vino, no solo a cortar y arrancar pedazos del paño que envolvía su rostro, pero también cortar sus cabellos y uñas, pedazos de las orejas y de los pezones (Huizinga, 2010, p. 270).

\section{De la muerte y de sus Representaciones}

Indudablemente, la mayor durabilidad y la falta de viscosidad dieron al esqueleto o al cráneo la posición de representantes del imaginario de la muerte. A lo largo de los siglos, 
con pocas excepciones, uno y otro son utilizados en las artes visuales, en las cenas y representaciones que se refieren a ella.

Durante el siglo XV, la idea de la muerte era ampliamente divulgada, tanto en poemas como en imágenes. Esto ocurre debido a un conjunto de factores que engloban el alto índice de mortalidad durante toda la Edad Media, cuyo apogeo fue la epidemia de la peste negra que diezmó millones de personas en el siglo XIV. La predicación religiosa, que al establecer la dualidad entre cuerpo y alma y privilegiar el alma en detrimento del cuerpo, alardeaba en todas las ocasiones posibles la idea de la perpetuidad del alma y del cuerpo perecedero y degenerante; y del surgimiento en el siglo XII de las ordenes mendicantes. Formadas por frailes y monjas estas órdenes religiosas, volteadas a difundir los enseñamientos de los Evangelios, predicaban para la población laica, para aquellos que no conocían profundamente las escrituras. La confluencia en las imágenes, de las muertes reales junto con un discurso religioso, hizo que éstas poseyeran gran poder de persuasión y, consecuentemente, que fueran ampliamente divulgadas. "Ininterrumpidamente, el llamado memento mori [recuerdos de muerte] resuena por la vida” (Huizinga, 2010, p. 221). De acuerdo con el autor, en este periodo, tres temas recurrentes abordaban "el final de toda la gloria terrena"

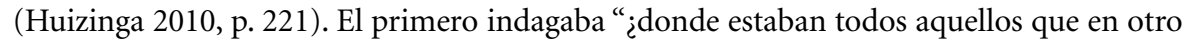
tiempo llenaban el mundo con su gloria?”(Huizinga 2010, p. 221). El segundo abordaba la descomposición de la belleza humana. El tercero introducía la imagen de la danza macabra.

\section{Danza Macabra}

Diseminada por las artes visuales de este periodo, por atender a todos los requisitos expuestos, la llamada danza macabra representaba una cena en la cual los vivos, independiente del cargo y de la posición social que ocupaban eran conducidos a la muerte por seres descarnados. En la representación se intercalaban muertos/esqueletos y vivos. Mientras los muertos danzaban, los vivos aparecen entorpecidos, inmovilizados delante del acontecimiento inesperado de la muerte.

El arte reside en el contraste del ritmo de los muertos y la paralización de los vivos. El objetivo oral es al mismo tiempo recordar la incertidumbre de la hora de la muerte y la igualdad de los hombres frente a ella (Ariès, 2014, p. 151-152).

Nacida del poema Respit de la Mort, anteriormente mencionado, la expresión danza macabra se volvió bastante conocida a partir del momento que nombró a esas imágenes. En ellas la introducción de la figura del esqueleto, acrecentaba a la imagen la cualidad de horrendo, tétrico, funesto; o sea, las características comprendidas en el término macabro. El poder, que estas imágenes tenían, de atemorizar a quienes las veían, y con el objetivo de conquistar nuevos fieles y mantener los antiguos obedientes a los preceptos predicados por la religión, lo macabro fue fácilmente cooptado por la iglesia. De acuerdo a Huizinga: "El concepto religioso omnipotente lo transformó [a lo macabro] en moral, convirtiéndolo en memento mori, pero le gustaba usar toda la sugerencia horripilante que el carácter de espectro que la imagen traía consigo"(Huizinga 2010, p. 231). 


\section{Vanitas}

En los siglos XVI y XVII surgen en las artes visuales las vanitas, del latín vanĭtas, àtis "vanidad, futilidad". Recordatorios contumaces de la mortalidad y de la inutilidad de la vanidad humana, tales representaciones se juntaban con elementos cotidianos, tanto orgánicos, por ejemplo, flores y frutas; como inorgánicos, por ejemplo, libros, instrumentos musicales, monedas, perlas, etc.; representaciones, por ejemplo, relojes, relojes de arena, etc.; que evidenciaban lo efímero de la vida, "la fuga del tiempo, las ilusiones del mundo" (Ariès, 2014 , p. 434), la transitoriedad de las acciones humanas en contraste con la fe. Esqueletos, cráneos o tibias, por ser los representantes máximos de la muerte como la vencedora final, eran los protagonistas de estas representaciones. Elementos supremos e indispensables de las vanitas.

Al principio, la exposición de estas imagines estaba limitada al dominio religioso. Ellas eran presentadas en las iglesias, en los osarios, en los túmulos y en los libros de las horas libro devocional, con ilustraciones, que contenían las fechas de las fiestas de los Santos, el horario asignado a los santos, oraciones y salmos penitenciales. Sin embargo, el gusto por estas imágenes hizo que éstas invadieran el mundo secular y pasaran a ser vistas en las residencias. El convivio íntimo y constante con estas imágenes que al presentificar el mensaje proferido por la religión, reforzaba el poder de la iglesia sobre los individuos. "Vanidad de las vanidades!, dice el Eclesiastés, todo es vanidad" (Eclesiastes 12: 8).

La iniciativa de desmembrar el esqueleto y de utilizar uno u otro hueso, venia al encuentro de la utilización domestica de las vanitas. La posibilidad de representar el todo utilizando solamente una de sus partes, es decir, de representar el esqueleto usando apenas uno de sus huesos, permitía disminuir las dimensiones de la figura a ser presentada, sin interferir en su visualización.

La mutilación del esqueleto propiciaba que la representación de la muerte estuviera presente, no solamente en objetos de tamaños grande o mediano, pero también en pequeñas pinturas y en objeto de uso cotidiano y personal.

El cráneo y las tibias destacados, multiplicados como una especie de algebra o de heráldica combinadas -además- con otros signos como: el reloj de arena, el reloj, la guadaña, la azada del sepulturero... Estos signos invadieron, entonces no sólo el arte funerario, más los objetos familiares que son las vanidades (Ariès, 2014, p. 435).

Al tornarse representaciones pertenecientes al universo familiar, los huesos pasaron también a ser expuestos en los retratos. Aparecían al lado del retratado -sobre algún mueble u objeto de uso personal- o en sus manos. Con eso, el elemento orgánico para explicitar el declive de la vida, diferentemente de las imágenes difundidas anteriormente, en las cuales esta posición era ocupada por flores o frutas, pasa a ser el cuerpo humano.

El gran cambio implementado por los retratos es que en ellos lo que apunta a la degeneración es uno de los últimos elementos del cuerpo, juntamente con los cabellos, a descomponerse. Flores y frutas representan sus totalidades y se pudren rápidamente; huesos y cabellos no. Al exponer la degradación del cuerpo humano a través de la representación 
limpia de los huesos y no de la representación infectante de la podredumbre de la carne, las imágenes se vuelven agradables. La aceptación y, consecuentemente, la difusión doméstica de las vanitas, ciertamente, sería diminuta, si la elección recayera sobre la representación del proceso de putrefacción de la carne y/o de las vísceras.

La elección de las partes secas, primeramente de los huesos, por no despertar en los individuos la sensación de nausea, posibilitó que el elemento escogido para representar a la muerte -que indica cómo cada uno de los seres, sin excepción, acabaría- y difundir la palabra de la inutilidad de la valoración humana a la vanidad, la "cualidad de lo que es vano, vacío, asentado sobre la apariencia ilusoria"3, saliera de los espacios públicos, entrara a los privados y fuera sobrepuesto a los cuerpos de los vivos en formas de accesorios u joyas. Según Ariès, el padre reformador dominicano Girolamo Savonarola (1452-1498) llegó a recomendar que los fieles llevaran siempre consigo "un pequeño cráneo de hueso, al cual se debería mirar frecuentemente" (2014, p. 437). Es Jean de Ditenville (1504-1555), embajador de Francia en Inglaterra en 1533, quien en el retrato "Los Embajadores" -pintado en esta fecha por Hans Holbein- llevaba un adorno en forma de cráneo en el sombrero. En este cuadro el cráneo no está presente solamente en la indumentaria del embajador; éste aparece también pintado de forma destorcida -visible solamente si el observador se posiciona a la derecha de la obra- entre Ditenville y el otro individuo retratado en la tela, el obispo de Lavaur, George de Selve.

La imposibilidad de seguir la recomendación dada por el padre Savonarola, de poseer adornos confeccionados a partir de materia prima genuina -en este caso huesos humanos- o utilizar el propio elemente como adorno, hace que los orfebres y joyeros de la época se dediquen a reproducir estos elementos en metales preciosos -oro y plata- piedras preciosas, esmaltes, etc.

En Inglaterra, en ese mismo periodo, surgen anillos adornados con temas macabros. Según Ariès, entre estos están los llamados anillos de luto, cuyo ajuste era hecho con la imagen del cráneo y las tibias cruzadas y se los ofrecía, junto con guantes, a las personas que asistían a funerales en Nueva Inglaterra.

A la gama de reproducciones hechas como adornos personales, siguió la de reproducciones e inscripciones hechas en las fachadas de las casas, más precisamente en la toca de la chimeneas, en muebles y, más tarde en el siglo XIX, incluso en las vajillas, cuando la imagen de esqueletos fueron impresas en platos de loza. "La muerte es, entonces, fundida en la existencia frágil y vana de las cosas; ya, en la Edad Media, ella venia de afuera" (Ariès, 2014, p. 439).

\section{Cuerpo - De los postulados Religiosos y Médicos}

Con la apropiación del cuerpo por la medicina, él deja de ser conducido, exclusivamente, por la religión y pasa a ser regido, también, por la ciencia. Los episodios descritos a seguir, sobre el funcionamiento del cuerpo, se dieron en el periodo barroco, y son fundamentales para el cambio que ocurre en la forma de como el cuerpo pasa a ser comprendido.

Protagonista del primer episodio, el médico William Harvey descubre, en 1628, que la responsable para mantener la temperatura del cuerpo es la circulación sanguínea. Y que 
ésta se da por el movimiento sincrónico comendado por el corazón y llevado a cabo por los pulmones, arterias y venas. Comparado por Harvey a una máquina, el corazón barroco entra en conflicto con el corazón exaltado por la visión cristiana medieval que lo denominaba "órgano de la compasión".

El segundo episodio ocurre cuando Thomas Willis, que también era médico, al investigar tejidos cerebrales, descubre que en respuesta a ciertos estímulos cerebrales, el cuerpo de animales y de personas recién muertas reaccionan similarmente. Como ambos no tenían alma, en los animales ellas son inexistentes y en los recién muertos ellas ya no habitan -conclúyase que no era ella la que regía el cuerpo. Tal conclusión hace recaer sobre el hombre, y no más sobre Dios, la responsabilidad de la manutención saludable del cuerpo. Estos dos acontecimientos marcan el cambio de los postulados que ejercen gerencia sobre el cuerpo y, consecuentemente, afectan la forma perceptiva de la muerte. Otro factor importante relacionado a las transformaciones en la forma cómo la muerte es percibida se debe al surgimiento de la consciencia individualista. Ocurrido al final de la Edad Media y desarrollado durante el renacimiento tal acontecimiento, que es anterior a las descubiertas médicas aquí descritas, coloca el individuo como responsable de sus actos, decisiones, fortuna. $\mathrm{Al}$ actuar conforme sus propios pensamientos y creencias los sujetos dejan de actuar, exclusivamente, conforme a las predeterminaciones sociales establecidas, pasan a crear sus propios destinos y a conducir sus propias muertes. Tal cambio hace con que la experiencia de la muerte deje la esfera de lo que es común y entre en el ámbito privado.

Si para esos hombres la sociedad no se dividía más en órdenes rígidas y estables, en las cuales los grupos comparten los mismos destinos, morir deja de ser considerado parte de esa suerte común y se transforma en un evento particular. Comienzan a no temer al fin de la vida en sí, pero si el proceso de la muerte: lo que se pierde y lo que se deja, cómo ocurrirá y qué vendrá después (Schimitt, 2010, p. 151).

Entre estos temores los que más exacerbaban los pensamientos y tiraban la tranquilidad de los individuos era referente a lo que sería hecho con sus cadáveres y como los recuerdos de sus existencias serian mantenidas. En relación al cuerpo, tal temor es justificado por el hecho de que él es la parte material por la cual nos hacemos reconocer. Preservar su imagen era fundamental para no extinguir su memoria.

De las varias formas utilizadas para que los muertos no fueran olvidados, daremos destaque a lo que se refiere al modo cómo pasaron a ser enterrados.

A partir del siglo XIX los espacios destinados a esta finalidad sufren modificaciones significativas. Ellos dejaron de ocupar áreas anexas a las iglesias y pasaron a ser implantados en terrenos específicamente a ellos destinados, en los cuales todas las dependencias, incluyendo la división de los lotes que contenían los túmulos, eran dispuestos conforme al trazado determinado por sus proyectos arquitectónicos.

Organizadas y privadas, las sepulturas pasaron a pertenecer a quien las compraba, eran el último lugar del muerto y de su familia. Eran ellas las que contenían el cuerpo del individuo, o sea, la parte material de su identidad y representante de su existencia. Para mantener el contacto con los muertos y preservar sus memorias, los túmulos comenzaron 
a ser cuidados y visitados. Conforme a Schimitt: "El protagonista del dolor de la muerte era ahora aquel que quedaba y no más el que agonizaba” (2010, p. 170).

Al ocupar el lugar del personaje principal, con el deseo de preservar la memoria del muerto a través de la personificación, aunque no estuviera visible el cuerpo, los coadyuvantes preservaban el túmulo y las imágenes en él, enaltecían sus bienes inmateriales, como materiales y llevaban consigo elementos que evidenciaban su pérdida.

\section{De los Adornos y de las Joyas de la Era Victoriana}

La era victoriana se extendió entre los años 1837 a 1901, inauguró formas, hasta entonces, inexistentes de percibir la muerte La dramaticidad de los preparativos que precedían su llegada, hechos por los familiares de aquellos que agonizaban y el ceremonial que sucedía a su concretización, mostraban el dolor y la angustia sentidas por los sobrevivientes frente a la finitud del otro.

En esta época, la exacerbación de los ritos y costumbres que la envolvían, era resultante del comportamiento de la reina Victoria, que profundamente afectada por la muerte -en 1861- de su esposo, el príncipe consorte Albert; instituyó varias normas restrictivas de conducta para el periodo de luto. Entre ellas, merece destaque, la utilización de vestimenta y accesorios de color negra por un largo espacio de tiempo. Las viudas deberían usar indumentaria negra por lo menos por dos años y medio. La propia Reina Victoria, inmersa en el sentimiento de pérdida, vivencio el luto y se vistió de negro hasta el momento de su muerte que ocurrió cuarenta años después. "El luto negro es la pérdida definitiva, la caída sin retorno en el nada (...)” (Chevalier y Gheerbrant, 2002, p. 741).

Siguiendo el comportamiento de la reina, el uso de las vestimentas negras dejó de contemplar solamente a los que pasaban por la experiencia del luto, se extendió por toda la población y se tornó uniforme de los aristócratas, industriales, comerciantes, profesionales liberales y operarios. Todos usaban negro, independientemente del sexo, la edad y la clase social. Situado fuera del sistema cromático por aproximadamente tres siglos, a partir del descubrimiento, entre 1670 y 1672, por Isaac Newton, el negro, del latin: prett- por pressus "apretado, prensado; perseguido de cerca; oculto, invisible; sombrío, oscuro"4, es asociado a la "oscuridad primordial, a la diferenciación original" (Chevalier y Gheerbrant, 2002, p. 74). En un primer momento se hizo la luz, lo blanco, y se aclaró la oscuridad. Siendo el color de lo interior de lo que se oculta, interno, profundo y representa a la falta de luz, el negro está ligado a la tierra, al espacio destinado tanto para la germinación, como para el entierro.

Negro y muerte están juntos desde hace mucho tiempo. Conforme Pastoureau (2011), desde el periodo Neolítico, cuando la utilización de piedras negras, pequeñas estatuas y objetos de colores oscuros, estaban asociados a ritos fúnebres. El mencionado autor sostiene:

Ese negro ctónico todavía no es ni diabólico ni maléfico; al contrario, se vincula a la dimensión profunda de la tierra: para el muerto a quien asegura el paso para la otra vida, se trata de un negro benéfico, signo o promesa de un renacimiento (Pastoureau, 2011, p. 28). 
El negro asociado con la muerte como un fin, y no como un renacimiento, es lo que predomina en los textos bíblicos. En éstos, en contraposición del blanco, está vinculado al mal, el castigo, al sufrimiento. Al final del siglo XIII, en el occidente, según Pastoureau (2011), el negro pasó a ser el color más utilizado para teñir los tejidos. Las vestimentas de uso cotidiano de aquellos que tenían algún tipo de poder: gobernadores, miembros de tribunales y de las cortes, juristas, etc. Pasan a ser de este color. Al usarlas se tenía el deseo de transmitir: seriedad, austeridad, virtud, autoridad, rectitud, etc.

Ninguna de estas cualidades salen de pauta con el uso del negro debido a la consternación causada por la muerte. Los individuos que se encuentran en el periodo que sigue al fallecimiento de alguien próximo, suman a éste significados simbólicos, los que fueron apuntados anteriormente y que hacen del negro el color occidental del luto.

La necesidad de preservar la memoria del muerto no era visible solamente en la integración de los cuerpos vivientes, del vestuario y conductas establecidos como apropiados para el periodo de luto. Ella se personificaba también en el retrato del muerto. No, en el retrato del muerto mientras vivo. $\mathrm{Si}$, en el retrato del muerto si está muerto.

En esta época se volvió una práctica fotografiar al muerto. Llamado de registro post-mortem, el procedimiento ocurría de la siguiente forma: el cadáver era vestido con sus mejores ropas y maquillado de modo para aparecer con un aspecto saludable, en seguida el cuerpo era colocado en una posición que remitía a la de un ser viviente -sentado, en pie, agarrando objetos, etc. En esas posiciones, solamente no eran puestos aquellos cuya causa mortis o rigor mortis lo impedía. En ese caso, eran echados y arreglados como si estuvieran descansando. Preso a la pared o apoyado sobre un mueble, el registro post-mortem eternizaba el cuerpo muerto y lo mantenía a salvo de la degeneración. Momia impresa en un papel que entre los vivos permanecía. "De esta manera, la fotografía certifica que el cadáver está vivo mientras está cadáver, es la imagen viva de una cosa muerta. Alma o muerto, haciéndolo posar forzosamente como vivo" (Schimitt, 2010, p. 178).

Preservar el cadáver -cuerpo muerto entero y no descompuesto- es lo equivalente a mantener vivo el cuerpo que está muerto. Contemporáneamente esta práctica viene resurgiendo. Los medios divulgaron recientemente algunos casos ocurridos en Puerto Rico de familias que embalsamaron sus muertos y los colocaron, durante sus velorios, representando acciones que les fueron placenteras durante la vida; como jugar póquer, andar de moto, luchar al box, etc. Las fotos que registraron estas representaciones, hechas por personas que fueron a los velorios, fueron colgadas en las redes sociales.

Entre las diferencias de las fotos en estos dos periodos, vale destacar que, mientras que las imágenes de la era victoriana eran todas posadas, el posicionamiento rígido era condicionado por el estado del cuerpo; en las contemporáneas, la ambición incide en retratar la espontaneidad gestual de los cuerpos que ya no la poseen.

Haciendo un paréntesis, es interesante que se recuerde la serie The Morgue, realizada en el inicio de la década de los 1990, por el fotógrafo americano Andrés Serrano. En ella nos presentan fotografías que retratan partes de cuerpos muertos que se encuentran en la morgue. Tales imágenes nos colocan frente a la causa mortis de seres desconocidos. Aun siendo fotografías de cadáveres, estas imágenes no tienen la finalidad de preservar entre los vivos, familiares o amigos, la imagen del cuerpo de aquellos que ya se fueron. Ellas 
actúan como asombrosas vanitas, para preservar en la memoria de los seres vivientes, su condición de seres mortales.

Para el filósofo anglo-irlandés Edmund Burke (1729-1797), el asombro es la pasión más intensa despertada por lo sublime. Burke (1993) clasificaba de sublime no lo que es extraordinario por ser superlativamente bello o estéticamente perfecto, pero si, lo que afecta de forma irremediable a los individuos.

Todo lo que sea de algún modo capaz de incitar las ideas o actúa de modo análogo al terror, constituye una fuente de lo sublime, esto es, produce la más fuerte emoción de que el espíritu es capaz. [Digo la más fuerte emoción, porque estoy convencido de que las ideas de dolor son mucho más poderosas de las que aquellas que provienen del placer (...)] (Burke, 1993, p. 48).

Volviendo a la era victoriana, para los individuos de este periodo, envolver el cuerpo con vestimenta negra y/o tener en casa el retrato del cuerpo sin vida de aquellos que les eran queridos, no fue suficiente para llenar el vacío dejado por sus muertes. Era necesario algo más. Era necesario traer consigo una parte del cuerpo de los fallecidos, o tenerlas expuestas en casa. Tal necesidad hizo surgir las llamadas joyas de luto. El principal elemento utilizado en la hechura de esas joyas eran los cabellos retirados de los cuerpos de aquellos que dejaron la vida. Herederas de las reliquias católicas que eran hechas con partes del cuerpo o de las ropas o de los objetos de tortura utilizados para martirizar los santos; estas joyas tornaban al individuo muerto presente, a través de parte de su cuerpo.

Simultáneamente junto con las joyas de luto surgieron adornos de casa hechos con cabello. Normalmente eran pequeños cuadros que podían representar escenas fúnebres, por ejemplo, el local del túmulo del muerto -en éstos los arboles eran hechos con cabellos- o cuadros en los que los cabellos envolvían el retrato del muerto, e inclusive, monogramas, arabescos y guirnaldas. Estas últimas eran colocadas con la parte abierta para arriba. Esta disposición simbolizaba la elevación al cielo del alma del fallecido. Las flores con las que se hacían estas guirnaldas eran confeccionadas con cabellos de los miembros de la misma familia enlutada. La flor que ocupaba la posición central en las guirnaldas era hecha con los cabellos del fallecido que se velaba.

Secos e imputrescibles, los cabellos desempeñaron su papel en la joyería de luto y en los adornos residenciales. Así como los huesos lo hicieron en las danzas macabras y en las vanitas. Mientras éstas recordaban la finitud de la vida y predicaban contra las vanidades, los primeros personificaban a los muertos a través de sus cuerpos.

Es importante resaltar que las joyas hechas con cabellos no fueron una invención de la era victoriana y no estaban restrictas al luto. Este mismo material era utilizado también, para hacer joyas que simbolizaban y exaltaban la amistad y el afecto. Estas joyas, llamadas "Hair Work", eran ofrecidas entre personas que componían una pareja, amigos y familiares.

En la contemporaneidad, algunos artistas visuales y diseñadores de joyas, como Kerry Howley -que desarrolló en 2011, la colección "Atração/Aversão"- o Sybille Paulsen -que desarrolla la colección "Verdades Tangiveis"- utilizan este mismo material -cabellos humanos- como materia prima para confeccionar adornos corporales. La primera de estas colecciones, compuesta por cinco collares, fue desarrollada por Howley con cabellos de 
una única persona -la madre de un amigo- que se los donaron para ella. La idea, que tenía como principio explorar el proceso por el cual un estímulo puede provocar simultáneamente respuestas emocionales aparentemente opuestas -atracción, aversión- tuvo su origen en el interés de la diseñadora en la observación de freak shows y en las costumbres victorianas relacionadas a la muerte.

Materia prima perfecta para cumplir tal objetivo, el cabello, dependiendo de su estado -vivo o muerto- evoca la dicotomía expresada en el título de la colección. Las piezas desarrolladas por la diseñadora pueden ser adquiridas y usadas por personas que no conocen y no tienen ninguna relación con la donadora del cabello. La segunda colección, creada por Paulsen, difiere totalmente de la primera, tanto en lo que se refiere a la motivación del origen, a las sensaciones que despierta. La principal materia prima utilizada en esta colección son cabellos de mujeres sometidas a quimioterapia. El proceso de hechura es de la siguiente forma: las donadoras, que serán también las usuarias de las joyas, cortan sus cabellos y los entregan a la diseñadora juntamente con declaraciones sobre sus intereses, sus afectos y sus gustos.

A partir de estas declaraciones, Paulsen escoge los demás materiales que serán utilizados en la hechura del adorno -estos materiales no necesariamente pertenecen al cuerpo humano- y darán forma a la joya. El objetivo de la diseñadora es crear estos objetos y devolver a las mujeres parte de lo que les fue tirado a rebeldía y marcar la transformación que ocurrió en sus vidas durante este periodo. Las joyas confeccionadas con cabellos humanos -elemento innato de la especie y detentador de una gran carga simbólica- independientemente de la época en la que fueron hechas, de los motivos que las originan y que son sobrepuestas a cuerpos de desconocidos o usadas por los propios donadores de la materia prima, siempre afectan a sus observadores de modo complejo y siempre despiertan reacciones antagónicas de aproximación y distanciamiento, de empatía y repulsión; o como bien dice el nombre de la colección desarrollada por Howley, de atracción y aversión.

Si se considera que uno de los significados simbólicos del cabello es ser depositario de las memorias del individuo cuyo organismo los desarrolló, se desprende que todo adorno hecho con cabellos lleva consigo estas memorias. De esta manera, como guardianes de las memorias y sueños, estos adornos mezclan a la conciencia del individuo que los usa recuerdos pertenecientes a los seres que los generaron. Joya recuerdo, que se presenta de diferentes formas.

\section{Notas}

1. Grande Dicionário Houaiss da Língua Portuguesa. Versão Digital.

2. Grande Dicionário Houaiss da Língua Portuguesa. Versão Digital.

3. Grande Dicionário Houaiss da Língua Portuguesa. Versão Digital.

4. Grande Dicionário Houaiss da Língua Portuguesa. Versão Digital. 


\title{
Referencias Bibliográficas
}

Agamben, G. (2006). A Linguagem e a Morte. Belo Horizonte: UFMG.

Ariès, P. (2014). O Homem Diante da Morte. São Paulo: UNESP.

Bíblia Sagrada Católica. Versão Digital.

Burke, E. (1993). Uma Investigação Filosófica sobre a Origem de nossas Idéias do Sublime e do Belo. Campinas: Papirus.

Chevalier, J. e Gheerbrant, A (2002). Dicionário de Símbolos. Rio de Janeiro: José Olympio.

Grande Dicionário Houaiss da Língua Portuguesa. Versão Digital.

Huizinga, J. (2010). O Outono da Idade Média. São Paulo: Cosac Naify.

Pastoureau, M. (2011). Preto - A História de uma Cor. São Paulo: SENAC.

Pires, B. F. (2005). O Corpo como Suporte da Arte - Piercing, Implante, Escarificação, Tatuagem. São Paulo: SENAC.

Schimitt, J. (2010). Mortes Vitorianas. São Paulo: Alameda.

\begin{abstract}
Openly, the Victorian Era imposed mourning on the society; it established black as the official color of mourning clothing, and it introduced to the market the production of ornaments, both residential and for personal use, made of human hair. Such ornaments, made of an organic raw material taken from the body of a dear relative, assured that this one would not be forgotten. Nowadays, this same material is been used by some contemporary jewelry designers.

The possibility to use human raw material to make these ornaments, takes place throughout the centuries, because of the changes in the perceptions towards death and how is it represented; how the death body is taken care and buried.
\end{abstract}

Keywords: Hair - Mourning Jewelry - Death - Middle Ages - Victorian Era.

Resumo: A era vitoriana colocou o luto em pauta, padronizou o preto como cor oficial das vestimentas e inseriu no mercado a produção de adornos, tanto residenciais, como corporais, confeccionados com cabelos humanos. Tais adornos, ao serem feitos com matérias-primas orgânicas, provenientes do corpo de um ente querido, garantiam que este não fosse esquecido. Contemporaneamente, este mesmo material é utilizado por alguns designers de joias.

A possibilidade de utilizar material humano para confeccionar estes ornamentos ocorre devido às mudanças na forma como, ao longo dos séculos, a morte foi percebida e representada, como o corpo morto foi cuidado e inumado.

Palavras chave: Cabelos - Joias de Luto - Morte - Idade Média - Era Vitoriana.

[Las traducciones de los abstracts fueron supervisadas por el autor de cada artículo] 